Article

\title{
Tortuosity of the Internal Carotid Artery and Its Clinical Significance in the Development of Aneurysms
}

\author{
Kornelia M. Kliśs ${ }^{1,2,3}$, Roger M. Krzyżewski ${ }^{3,4, *}$, Borys M. Kwinta ${ }^{3,4}$ (D), Krzysztof Stachura ${ }^{4}$ \\ and Jerzy Gąsowski 3,5 \\ 1 Faculty of Medicine, Jagiellonian University Medical College, 31-008 Kraków, Poland; \\ korneliakli@gmail.com \\ 2 Faculty of Computer Science, Electronics and Telecommunications, AGH University of Science and \\ Technology, 30-059 Kraków, Poland \\ 3 TENSOR-Team of NeuroSurgery-Oriented Reaserch, Jagiellonian University Medical College, \\ 31-008 Kraków, Poland; bmkwinta@gmail.com (B.M.K.); jerzy.gasowski@gmail.com (J.G.) \\ 4 Department of Neurosurgery and Neurotraumatology, Jagiellonian University Medical College, \\ 31-503 Kraków, Poland; kkstach@poczta.onet.pl \\ 5 Department of Internal Medicine and Gerontology, Jagiellonian University Medical College, \\ 31-531 Kraków, Poland \\ * Correspondence: roger.krzyzewski@gmail.com
}

Received: 26 December 2018; Accepted: 1 February 2019; Published: 12 February 2019

\begin{abstract}
Tortuosity of blood vessels is a common angiographic finding that may indicate systemic disease and can be correlated with vascular pathologies. In this work, we determined whether patients with and without internal carotid artery (ICA) aneurysm presented with differences in its tortuosity descriptors. We retrospectively analysed data of 298 patients hospitalized between January 2014 and June 2018. For each patient's imaging data, we extracted a curve representing the ICA course and measured its Relative Length (RL), Sum of Angle Metrics (SOAM), Product of Angle Distance (PAD), Triangular Index (TI), and Inflection Count Metrics (ICM). We found that patients with an ICA aneurysm had significantly lower RL $(0.46 \pm 0.19$ vs. $0.51 \pm 0.17 ; p=0.023)$ and significantly higher SOAM $(0.39 \pm 0.21$ vs. $0.32 \pm 0.21 p=0.003)$, $\operatorname{PAD}(0.38 \pm 0.19$ vs. $0.32 \pm 0.21 ; p=0.011)$, TI $(0.30 \pm 0.11$ vs. $0.27 \pm 0.14 ; p=0.034)$, and ICM $(0.30 \pm 0.16$ vs. $0.22 \pm 0.12 ; p<0.001)$. We found that that patients who presented with a subarachnoid hemorrhage had significantly higher PAD $(0.46 \pm 0.22$ vs. $0.35 \pm 0.20 ; p=0.024)$. In conclusion, higher tortuosity of ICA is associated with ICA aneurysm presence.
\end{abstract}

Keywords: intracranial aneurysm; tortuosity; internal carotid artery

\section{Introduction}

Tortuosity of blood vessels is a common angiographic finding that might indicate systemic diseases, such as hypertension or diabetes mellitus [1,2], and can be correlated with vascular pathologies [3,4]. It can also increase with age [5]. Tortuosity is most commonly analysed in retinal and coronary vessels; however, it can be found in a vast majority of blood vessels [6]. In terms of brain vasculature, tortuosity is associated with Moyamoya disease [7] and presence of atherosclerosis [8]. Sprangler et al. found a correlation between hypertension and white matter arterioles [9].

A few mechanisms may be linked to an increase in tortuosity, the first of which are mechanical factors of blood flow, such as elevated blood pressure [2] or reduced axial tension [6]. Another factor that might promote tortuosity is the weakening of arterial walls, resulting either from elastin 
degradation or abnormal deposits within vessel walls [10]. Tortuosity could also result from an increase in blood flow [2].

As tortuosity promotes hemodynamic changes in blood flow, it can lead to the development of aneurysms. Such association was found in terms of the aorta [11] and splenic artery [12], as well as in brain arteries, such as the internal carotid artery (ICA) [13], basilar artery (BA) [14], middle cerebral artery (MCA) [15], and vertebral artery [16]. Our previous study suggested that tortuosity of the anterior cerebral artery might play a role in anterior communicating artery aneurysm rupture [17]. However, some of the authors who analysed tortuosity used subjective methods based on visual appearance [13]. Therefore, we decided to perform a computer-aided analysis of ICA and objectively determine whether there is a difference in mathematical tortuosity factors between groups of patients with and without ICA aneurysm.

\section{Experimental Section}

We retrospectively analysed the data of 298 patients hospitalized between January 2014 and June 2018 who underwent digital subtraction angiography (DSA) due to suspicion of an intracranial aneurysm. Our study group included 149 patients with ICA aneurysm and 149 patients in the control group without ICA aneurysm, matched for age ( \pm 3 years) and risk factors (hypertension, diabetes mellitus, and smoking). Aneurysm presence was confirmed by DSA. Patients with multiple aneurysms, ICA aneurysms located in extracranial segment, suspicion of intracranial vasospasm, connective tissue disorders, or patients who did not provide informed consent to participate in the study were excluded. For each patient, we obtained their medical history from their medical records, including previous and current diseases and medications, as well as aneurysm data such as its size and exact location. Mirror aneurysms were defined as both-sided aneurysms on the same segment of ICA. We obtained patients' imaging data prior to surgical or endovascular treatment. The study protocol was approved by a local bioethical committee and all patients provided informed consent. Database and source code of the used software are available to readers upon request. The primary endpoint for our study was to determine an association between tortuosity of intracranial segments of ICA and presence of ICA aneurysm. Secondary endpoints included determining a possible association between ICA tortuosity and common risk factors for aneurysm development, as well as between ICA tortuosity and ICA measurements.

Methods of artery tracking and details about the software used for this study were described in our previous work [15]. For each patient's DSA, we extracted a curve representing the ICA intracranial course (C2-C7 segments) and measured its Relative Length (RL), Sum of Angle Metrics (SOAM), Product of Angle Distance (PAD), Triangular Index (TI), and Inflection Count Metrics (ICM). The formulas for each descriptor calculation are presented in Figure 1. We measured diameters of ICA segments C6 and C7 as well as the mean diameter of the entire ICA obtained from its three measurements $-2 \mathrm{~mm}$ from each end and in the middle. 


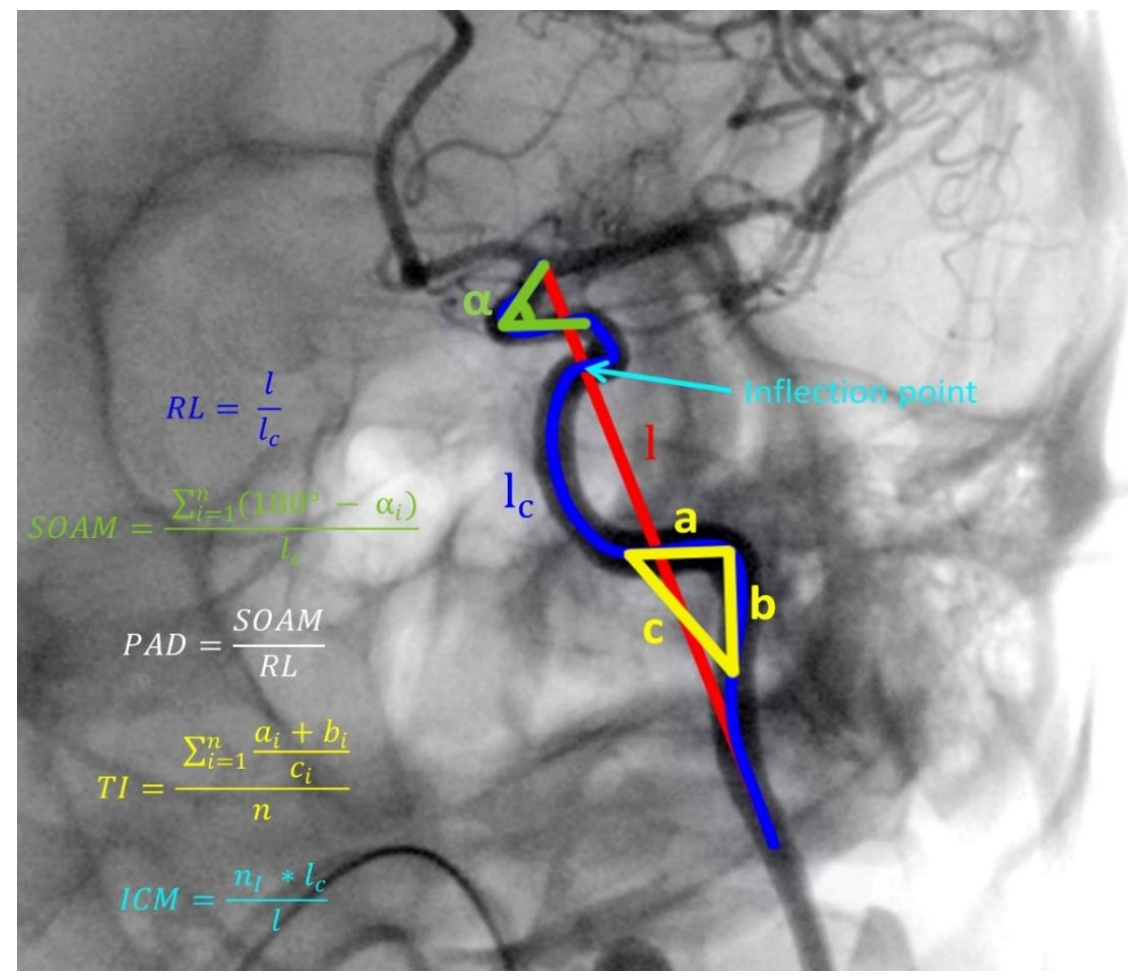

Figure 1. Illustration of internal carotid artery (ICA) tracking and tortuosity descriptors calculation. RL, Relative Length; SOAM, Sum of Angle Metrics; PAD, Product of Angle Distance; TI, Triangular Index; ICM, Inflection Count Metrics; $n$, number of angles on ICA course; an $\mathrm{d} n{ }_{i}$, number of inflection points on ICA course. Marked angle, triangle, and inflection point are exemplary and are applicable to all parts of the artery. 1, length of straight line between starting and ending point of analyzed artery segment; $1_{c}$, absolute length of analyzed artery segment; $a, b$ and c, sides of triangle constructed on angle of analyzed artery segment; $\alpha$, angle of analyzed artery segment.

The database management and statistical analysis were performed with RStudio version 8.5 for Windows (RStudio, Inc., Boston, MA, USA). We used the Shapiro-Wilk test to assess normality. For comparisons of continuous variables, we used the $t$-test for normally distributed variables, and the Mann-Whitney $U$ test for non-normally distributed variables. We used the $\chi^{2}$ test for dichotomous variables. To assess correlation between continuous variables, we used Pearson's or Spearman's correlation tests for normally and non-normally distributed variables, respectively. We express continuous variables as a mean (standard deviation). To find factors independently associated with the presence of an ICA aneurysm, we employed logistic regression analysis with and without adjustment for possible confounders. All significance tests are two-tailed and a $p$-value $<0.05$ was considered significant.

\section{Results}

\subsection{Study Group Characteristics}

Our study group included 298 patients and 227 (76.17\%) were women. The mean age of the study group was $57.48 \pm 12.66$ years. Among the patients in the study group, the mean diameter of the C6 segment was $3.88 \pm 0.86 \mathrm{~mm}$, the mean diameter of the C7 segment was $2.92 \pm 0.72 \mathrm{~mm}$, the mean diameter of MCA was $1.93 \pm 0.57 \mathrm{~mm}$, and the mean ACA diameter was $1.75 \pm 0.48 \mathrm{~mm}$. In terms of tortuosity, average RL was $0.48 \pm 0.19$, average SOAM was $0.36 \pm 0.21$, average PAD was $0.35 \pm 0.20$, average TI was $0.29 \pm 0.13$, and average ICM was $0.26 \pm 0.14$. Among patients with an ICA aneurysm, the most common location of the aneurysm was the C7 segment $(49.62 \%)$, then the C6 segment (39.10\%), C4 segment (9.02\%), and C5 segment (2.26\%). Eighty-four (56.38\%) aneurysms were 
located on the right side, 78 (52.35\%) aneurysms were located on left side, and 21 aneurysms (14.09\%) were mirror aneurysms. The mean size of the aneurysm dome was $7.19 \pm 4.89 \mathrm{~mm}$ and the mean size of the aneurysm neck was $2.98 \pm 1.18 \mathrm{~mm}$.

\subsection{Risk Factors for Aneurysm Presence}

Our study showed that ICA aneurysms were more common in women $(83.89 \%$ vs. $68.46 \%$; $p=0.002)$. Subarachnoid hemorrhage was also more common in women than men $(9.40 \%$ vs. $2.68 \%$; $p=0.015)$. Women were also significantly less likely to have a history of ischemic stroke $(4.70 \%$ vs. $14.09 \% ; p=0.005)$. Additionally, for patients with ICA aneurysm more commonly consumed acetylsalicylic acid $(26.17 \%$ vs. $12.08 \% ; p=0.002), \mathrm{AT}_{2}$-blockers $(2.68 \%$ vs. $0 \% ; p=0.044)$, and statins $(8.72 \%$ vs. $2.68 \% ; p=0.025)$. We found that the $\mathrm{C} 6$ segment diameter was significantly smaller in these patients ( $3.77 \pm 0.88 \mathrm{~mm}$ vs. $3.99 \pm 0.82 \mathrm{~mm} ; p=0.023)$. In terms of tortuosity descriptors, patients with an ICA aneurysm presented with a significantly lower RL ( $0.46 \pm 0.19$ vs. $0.51 \pm 0.17 ; p=0.023)$, and significantly higher SOAM $(0.39 \pm 0.21$ vs. $0.32 \pm 0.21 p=0.003), \operatorname{PAD}(0.38 \pm 0.19$ vs. $0.32 \pm 0.21$; $p=0.011)$, TI ( $0.30 \pm 0.11$ vs. $0.27 \pm 0.14 ; p=0.034)$, and ICM $(0.30 \pm 0.16$ vs. $0.22 \pm 0.12 ; p<0.001)$ (Table 1, Figure 2).

Table 1. Comparison of risk factors and tortuosity descriptors between patients with and without internal carotid artery aneurysm.

\begin{tabular}{|c|c|c|c|}
\hline Variable & ICA Aneurysm $(n=149)$ & No ICA Aneurysm $(n=149)$ & $p$-Value \\
\hline Female sex $(\%)$ & $83.89(125)$ & $68.46(102)$ & 0.002 \\
\hline Age (years) $\pm S D$ & $57.49 \pm 12$ & $57.48 \pm 13.32$ & 0.993 \\
\hline \multicolumn{4}{|l|}{ Risk Factors } \\
\hline Diabetes mellitus (\%) & $9.40(14)$ & $12.08(18)$ & 0.454 \\
\hline Smoking $(\%)$ & $12.75(19)$ & $12.75(19)$ & 0.999 \\
\hline Hypertension (\%) & $47.65(71)$ & $47.65(71)$ & 0.999 \\
\hline Alcoholism (\%) & $0(0)$ & $4.70(7)$ & 0.007 \\
\hline Ischemic heart disease (\%) & $1.34(2)$ & $3.36(5)$ & 0.251 \\
\hline History of heart attack (\%) & $0.67(1)$ & $2.68(4)$ & 0.176 \\
\hline History of ischemic stroke (\%) & $4.70(7)$ & $14.09(21)$ & 0.005 \\
\hline History of subarachnoid hemorrhage (\%) & $9.40(14)$ & $2.68(4)$ & 0.015 \\
\hline Atrial fibrillation (\%) & $1.34(2)$ & $2.01(3)$ & 0.652 \\
\hline Lungs diseases $(\%)$ & $4.70(7)$ & $4.03(6)$ & 0.777 \\
\hline Hyperthyroidism (\%) & $2.68(4)$ & $2.01(3)$ & 0.702 \\
\hline Hypothyroidism (\%) & $3.36(5)$ & $4.70(7)$ & 0.556 \\
\hline Hypercholesterolemia (\%) & $5.37(8)$ & $8.05(12)$ & 0.354 \\
\hline \multicolumn{4}{|l|}{ Current Medications } \\
\hline ASA (\%) & $26.17(39)$ & $12.08(18)$ & 0.002 \\
\hline$\beta$-blockers $(\%)$ & $14.09(21)$ & $15.44(23)$ & 0.744 \\
\hline ACEI (\%) & $18.12(27)$ & $10.74(16)$ & 0.070 \\
\hline $\mathrm{AT}_{2}$-blockers $(\%)$ & $2.68(4)$ & $0(0)$ & 0.044 \\
\hline Calcium channel blockers (\%) & $6.04(9)$ & $5.37(8)$ & 0.803 \\
\hline Diuretics $(\%)$ & $9.4(14)$ & $8.05(12)$ & 0.681 \\
\hline Steroids $(\%)$ & $2.01(3)$ & $0.67(1)$ & 0.314 \\
\hline Antidiabetic therapy (\%) & $4.03(6)$ & $2.68(4)$ & 0.520 \\
\hline Insulin $(\%)$ & $1.34(2)$ & $2.68(4)$ & 0.409 \\
\hline Heparin $(\%)$ & $0.67(1)$ & $0.67(1)$ & 0.999 \\
\hline Anticoagulants (\%) & $5.37(8)$ & $6.04(9)$ & 0.803 \\
\hline Nitrates $(\%)$ & $0.67(1)$ & $0(0)$ & 0.316 \\
\hline Statins $(\%)$ & $8.72(13)$ & $2.68(4)$ & 0.025 \\
\hline \multicolumn{4}{|l|}{ Artery Sizes } \\
\hline Mean ICA diameter $\pm \mathrm{SD}(\mathrm{mm})$ & $4.01 \pm 1.01$ & $4.07 \pm 1.18$ & 0.617 \\
\hline $\mathrm{C} 6$ segment diameter $\pm \mathrm{SD}(\mathrm{mm})$ & $3.77 \pm 0.88$ & $3.99 \pm 0.82$ & 0.023 \\
\hline $\mathrm{C} 7$ segment diameter $\pm \mathrm{SD}(\mathrm{mm})$ & $2.88 \pm 0.77$ & $2.95 \pm 0.67$ & 0.392 \\
\hline \multicolumn{4}{|l|}{ Tortuosity Descriptors } \\
\hline Relative Length \pm SD & $0.46 \pm 0.19$ & $0.51 \pm 0.17$ & 0.023 \\
\hline Sum of Angle Metrics \pm SD & $0.39 \pm 0.21$ & $0.32 \pm 0.21$ & 0.003 \\
\hline Product of Angle Distance \pm SD & $0.38 \pm 0.19$ & $0.32 \pm 0.21$ & 0.011 \\
\hline Triangular Index \pm SD & $0.30 \pm 0.11$ & $0.27 \pm 0.14$ & 0.034 \\
\hline Inflection Count Metric \pm SD & $0.30 \pm 0.16$ & $0.22 \pm 0.12$ & $<0.001$ \\
\hline
\end{tabular}

ICA, internal carotid artery; SD, standard deviation; ASA, acetylsalicylic acid; ACEI, angiotensin-converting-enzyme inhibitors; $\mathrm{AT}_{2}$-blockers, Angiotensin II receptor blockers. 


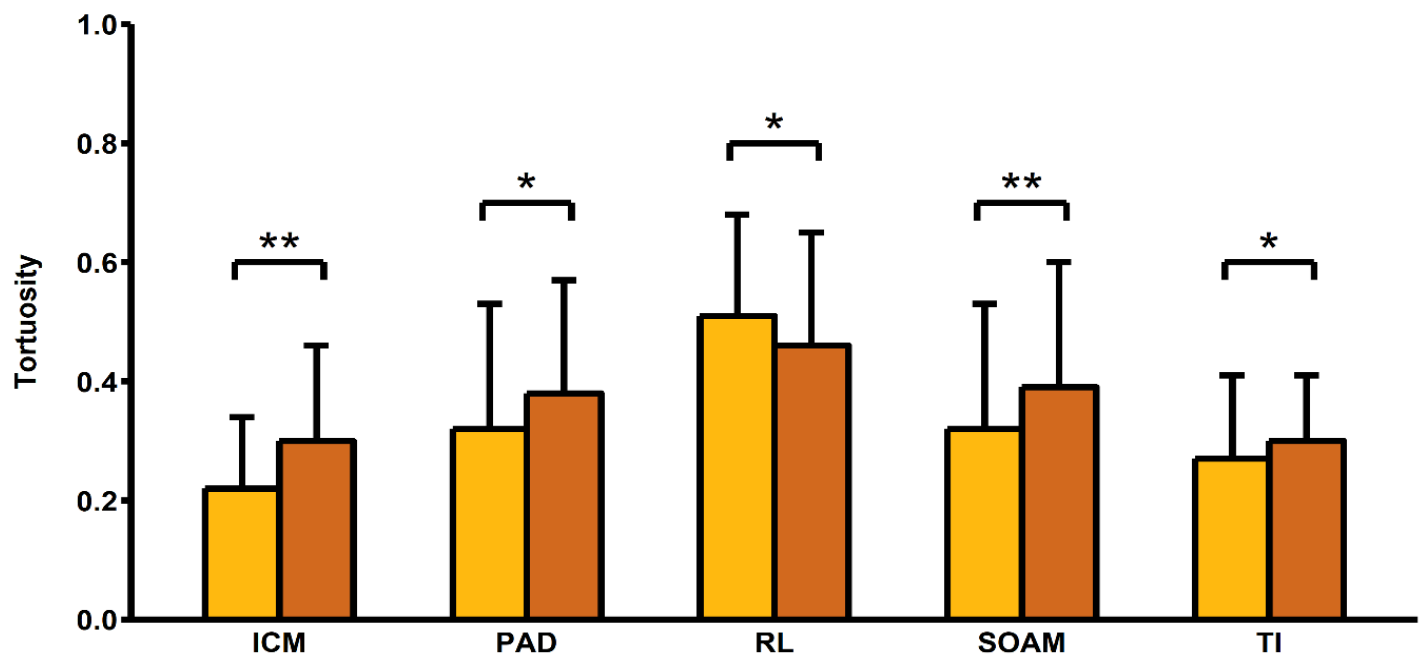

Figure 2. Comparison of tortuosity descriptors between patients with and without internal carotid artery aneurysm. ICA, internal carotid artery; RL, Relative Length; SOAM, Sum of Angle Metrics; PAD, Product of Angle Distance; TI, Triangular Index; ICM, Inflection Count Metrics; * $p$-value < 0.05; ** $p$-value $<0.01$.

\subsection{Association of Risk Factors with Tortuosity}

We found that female patients had a significantly higher SOAM $(0.37 \pm 0.21$ vs. $0.48 \pm 0.18$; $p=0.028), \operatorname{PAD}(0.37 \pm 0.20$ vs. $0.30 \pm 0.20 ; p=0.016)$, TI $(0.30 \pm 0.13$ vs. $0.25 \pm 0.10 ; p=0.006)$, and ICM $(0.27 \pm 0.15$ vs. $0.23 \pm 0.13 ; p=0.046)$. Our study showed that patients with a history of subarachnoid hemorrhage had significantly higher PAD $(0.46 \pm 0.22$ vs. $0.35 \pm 0.20 ; p=0.024)$ (Table 2). However, there were no significant differences in terms of tortuosity between patients with and without risk factors such as hypertension, diabetes mellitus, smoking, history of myocardial infarction, or history of ischemic stroke.

Table 2. Association of intracerebral aneurysm development risk factors with internal carotid tortuosity descriptors.

\begin{tabular}{cccc}
\hline Tortuosity Descriptor & $\begin{array}{c}\text { Women } \\
(\boldsymbol{n}=\mathbf{2 2 7})\end{array}$ & $\begin{array}{c}\text { Men } \\
(\boldsymbol{n}=\mathbf{7 1})\end{array}$ & $\boldsymbol{p}$-Value \\
\hline Relative Length \pm SD & $0.49 \pm 0.19$ & $0.48 \pm 0.18$ & 0.812 \\
Sum of Angle Metrics \pm SD & $0.37 \pm 0.21$ & $0.31 \pm 0.21$ & 0.028 \\
Product of Angle Distance \pm SD & $0.37 \pm 0.20$ & $0.30 \pm 0.20$ & 0.016 \\
Triangular Index \pm SD & $0.30 \pm 0.13$ & $0.25 \pm 0.10$ & 0.006 \\
Inflection Count Metric \pm SD & $0.27 \pm 0.15$ & $0.23 \pm 0.13$ & 0.046 \\
\hline & Hypertension & No hypertension & \\
\hline Relative Length \pm SD & $(\boldsymbol{n}=\mathbf{1 4 2 )}$ & $0.48 \pm 0.19$ & 0.900 \\
Sum of Angle Metrics \pm SD & $0.49 \pm 0.18$ & $0.35 \pm 0.20$ & 0.327 \\
Product of Angle Distance \pm SD & $0.37 \pm 0.22$ & $0.35 \pm 0.19$ & 0.543 \\
Triangular Index \pm SD & $0.36 \pm 0.21$ & $0.28 \pm 0.11$ & 0.210 \\
Inflection Count Metric \pm SD & $0.30 \pm 0.14$ & $0.25 \pm 0.13$ & 0.204 \\
\hline & $0.27 \pm 0.16$ & No diabetes Mellitus & $(\boldsymbol{n}=\mathbf{2 6 6})$ \\
\hline Relative Length \pm SD & Diabetes Mellitus & $0.49 \pm 0.19$ & 0.573 \\
Sum of Angle Metrics \pm SD & $(\boldsymbol{n}=\mathbf{3 2 )}$ & $0.36 \pm 0.21$ & 0.811 \\
Product of Angle Distance \pm SD & $0.47 \pm 0.16$ & $0.35 \pm 0.20$ & 0.953 \\
Triangular Index \pm SD & $0.35 \pm 0.21$ & $0.28 \pm 0.12$ & 0.372 \\
Inflection Count Metric \pm SD & $0.30 \pm 0.17$ & $0.26 \pm 0.15$ & 0.690 \\
\hline
\end{tabular}


Table 2. Cont.

\begin{tabular}{|c|c|c|c|}
\hline Tortuosity Descriptor & $\begin{array}{l}\text { Women } \\
(n=227)\end{array}$ & $\begin{array}{c}\text { Men } \\
(n=71)\end{array}$ & $p$-Value \\
\hline & $\begin{array}{l}\text { Smoking } \\
(n=38)\end{array}$ & $\begin{array}{l}\text { No Smoking } \\
(n=260)\end{array}$ & \\
\hline Relative Length \pm SD & $0.51 \pm 0.18$ & $0.48 \pm 0.19$ & 0.312 \\
\hline Sum of Angle Metrics \pm SD & $0.37 \pm 0.21$ & $0.36 \pm 0.21$ & 0.758 \\
\hline Product of Angle Distance \pm SD & $0.38 \pm 0.21$ & $0.35 \pm 0.20$ & 0.379 \\
\hline Triangular Index \pm SD & $0.27 \pm 0.11$ & $0.29 \pm 0.13$ & 0.324 \\
\hline \multirow[t]{2}{*}{ Inflection Count Metric \pm SD } & $0.26 \pm 0.13$ & $0.26 \pm 0.15$ & 0.989 \\
\hline & $\begin{array}{l}\text { Hypercholesterolemia } \\
\qquad(n=20)\end{array}$ & $\begin{array}{l}\text { No Hypercholesterolemia } \\
(n=278)\end{array}$ & \\
\hline Relative Length \pm SD & $0.52 \pm 0.17$ & $0.48 \pm 0.19$ & 0.403 \\
\hline Sum of Angle Metrics \pm SD & $0.31 \pm 0.20$ & $0.36 \pm 0.21$ & 0.268 \\
\hline Product of Angle Distance \pm SD & $0.31 \pm 0.20$ & $0.36 \pm 0.20$ & 0.336 \\
\hline Triangular Index \pm SD & $0.26 \pm 0.11$ & $0.29 \pm 0.13$ & 0.295 \\
\hline \multirow[t]{2}{*}{ Inflection Count Metric \pm SD } & $0.23 \pm 0.11$ & $0.26 \pm 0.15$ & 0.360 \\
\hline & $\begin{array}{l}\text { History of Heart Attack } \\
\qquad(n=5)\end{array}$ & $\begin{array}{l}\text { No History of Heart Attack } \\
\qquad(n=293)\end{array}$ & \\
\hline Relative Length \pm SD & $0.48 \pm 0.14$ & $0.48 \pm 0.19$ & 0.964 \\
\hline Sum of Angle Metrics \pm SD & $0.40 \pm 0.32$ & $0.36 \pm 0.21$ & 0.658 \\
\hline Product of Angle Distance \pm SD & $0.43 \pm 0.37$ & $0.35 \pm 0.20$ & 0.379 \\
\hline Triangular Index \pm SD & $0.26 \pm 0.08$ & $0.29 \pm 0.13$ & 0.653 \\
\hline \multirow[t]{2}{*}{ Inflection Count Metric \pm SD } & $0.21 \pm 0.07$ & $0.26 \pm 0.14$ & 0.447 \\
\hline & $\begin{array}{l}\text { History of Ischemic } \\
\text { Stroke }(n=28)\end{array}$ & $\begin{array}{l}\text { No History of Ischemic } \\
\text { Stroke }(n=270)\end{array}$ & \\
\hline Relative Length \pm SD & $0.48 \pm 0.16$ & $0.48 \pm 0.19$ & 0.883 \\
\hline Sum of Angle Metrics \pm SD & $0.36 \pm 0.22$ & $0.36 \pm 0.21$ & 0.999 \\
\hline Product of Angle Distance \pm SD & $0.33 \pm 0.23$ & $0.36 \pm 0.20$ & 0.545 \\
\hline Triangular Index \pm SD & $0.30 \pm 0.19$ & $0.29 \pm 0.12$ & 0.582 \\
\hline \multirow[t]{2}{*}{ Inflection Count Metric \pm SD } & $0.25 \pm 0.14$ & $0.26 \pm 0.14$ & 0.724 \\
\hline & $\begin{array}{l}\text { History of Subarachnoid } \\
\text { Hemorrhage }(n=18)\end{array}$ & $\begin{array}{l}\text { No history of Subarachnoid } \\
\text { Hemorrhage }(n=280)\end{array}$ & \\
\hline Relative Length \pm SD & $0.53 \pm 0.18$ & $0.48 \pm 0.19$ & 0.284 \\
\hline Sum of Angle Metrics \pm SD & $0.42 \pm 0.22$ & $0.35 \pm 0.21$ & 0.176 \\
\hline Product of Angle Distance \pm SD & $0.46 \pm 0.22$ & $0.35 \pm 0.20$ & 0.024 \\
\hline Triangular Index \pm SD & $0.30 \pm 0.08$ & $0.29 \pm 0.13$ & 0.733 \\
\hline Inflection Count Metric \pm SD & $0.25 \pm 0.13$ & $0.26 \pm 0.15$ & 0.828 \\
\hline
\end{tabular}

\subsection{Additional Findings}

A significant negative correlation between RL and mean ICA diameter $(r=-0.187 ; p=0.001)$ was found. A significant positive correlation of TI $(r=0.534 ; p=0.049)$ and ICM $(r=0.773 ; p=0.001)$ with time after subarachnoid hemorrhage $(\mathrm{SAH})$ was found among patients who had a history of $\mathrm{SAH}$. However, there was no significant correlation between tortuosity descriptors and age or other artery measurements. There was also no significant difference in terms of tortuosity between patients with different aneurysm locations. Our study showed that patients with mirror aneurysms had a significantly lower TI $(0.31 \pm 0.11$ vs. $0.25 \pm 0.09 ; p=0.026)$ than other patients with ICA aneurysms (Table 3). 
Table 3. Correlation of tortuosity descriptors and continuous variables.

\begin{tabular}{cccccc}
\hline Variable & RL & SOAM & PAD & TI & ICM \\
\hline Age (years) & 0.053 & 0.016 & 0.002 & 0.089 & 0.024 \\
$p$-Value & 0.371 & 0.791 & 0.973 & 0.131 & 0.682 \\
C6 segment diameter $(\mathrm{mm})$ & -0.040 & -0.070 & -0.084 & -0.082 & -0.016 \\
$p$-Value & 0.498 & 0.232 & 0.155 & 0.162 & 0.787 \\
C7 segment diameter $(\mathrm{mm})$ & -0.026 & 0.024 & 0.025 & 0.045 & 0.068 \\
$p$-Value & 0.659 & 0.683 & 0.668 & 0.444 & 0.245 \\
Mean ICA diameter $(\mathrm{mm})$ & -0.187 & -0.034 & -0.057 & 0.072 & 0.091 \\
$p$-Value & 0.001 & 0.562 & 0.335 & 0.219 & 0.123 \\
MCA diameter (mm) & 0.082 & -0.003 & 0.024 & -0.031 & -0.013 \\
$p$-Value & 0.162 & 0.965 & 0.680 & 0.596 & 0.827 \\
ACA diameter (mm) & 0.024 & 0.026 & 0.060 & -0.028 & 0.034 \\
$p$-Value & 0.681 & 0.663 & 0.309 & 0.635 & 0.568 \\
Time after SAH (months) & -0.437 & 0.447 & 0.229 & 0.534 & 0.773 \\
$p$-Value & 0.118 & 0.109 & 0.432 & 0.049 & 0.001 \\
\hline
\end{tabular}

RL, Relative Length; SOAM, Sum of Angle Metrics; PAD, Product of Angle Distance; TI, Triangular Index; ICM, Inflection Count Metrics; ICA, internal carotid artery; MCA, middle cerebral artery; ACA, anterior cerebral artery; $\mathrm{SAH}$, subarachnoid hemorrhage.

\section{Discussion}

Our study showed that patients with ICA aneurysms have significantly higher ICA tortuosity. Similar results were obtained by Labeyrie et al. [13]; however, they determined tortuosity based on visual appearance and not measurements. Therefore, tortuosity might have been assessed subjectively. Our study objectively proves this association in terms of all tortuosity descriptors and, therefore, in all types of tortuosity. In our previous study [15], a similar correlation was shown in the middle cerebral artery for RL, PAD, TI, and ICM. However, we achieved contradictory results for SOAM. Association between higher tortuosity and intracranial aneurysm was shown in terms of BA [14] and VA [16], as well as in terms of the splenic artery [12] and aorta [11]. One of the explanations for such correlation could be changes in hemodynamics caused by increase in tortuosity. We showed that more tortuous coronary vessels are characterized by lower wall shear stress (WSS) and prolonged relative residence time (RRT) [18]. Association of lower WSS with aneurysm development was shown in other studies [19]. Both lower WSS and prolonged RRT can promote an inflammatory response in the arterial wall and therefore lead to atherosclerotic changes $[18,20]$. This mechanism is confirmed by a study by Kim et al. [8], which showed that an increase in tortuosity of MCA is related to cerebral atherosclerosis. Weakening of the arterial wall caused by atherosclerotic plaques could result in aneurysm development [21]. Additionally, lower WSS promotes matrix metalloproteinases activation [22], which also plays a role in the formation of aneurysms [23]. Another explanation for the correlation shown in our study could be the fact that tortuosity can be caused by elevated blood pressure and blood flow [2], weakening of the arterial wall due to elastin degradation [10], and reduced axial tension [6]. All these factors could lead to aneurysm development.

Our study showed a significant association between the female sex and tortuosity. Similar findings were reported in terms of women older than 60 years old [24]. Higher vessel tortuosity in female patients was also found in our previous study concerning the middle cerebral artery [15], and in a study performed by Chiha et al. regarding coronary arteries [25]. Our findings might be explained by the fact that the anatomy of the circle of Willis differs between men and women. Horokoshi et al. found that type $\mathrm{P}$ of the circle of Willis is more common among women [26]. In that type of anatomy, the P1 segment of the posterior cerebral artery is missing, which might result in increased blood flow in the ICA. Lindekleiv et al. showed that women had higher blood flow velocities and wall shear stress (WSS) at the ICA bifurcation [27]. All these findings might explain the increase in tortuosity in the ICA. Higher tortuosity of ICA among female patients also explains the higher prevalence of ICA aneurysms among these patients, which was presented both in this and other studies [28,29]. 
Another interesting finding of our study is the higher ICA tortuosity in patients who had SAH. Tortuosity is correlated with the time after SAH onset. Such findings suggest that SAH promotes arterial remodeling, which might lead to an increase in tortuosity. SAH is related to an increase in matrix metalloproteinase 9 levels [30], which might promote extracellular matrix remodeling [31]. Degradation of extracellular matrix may be one of the causes of tortuosity increase [32]. SAH also causes an increase in proangiogenic markers, such as vascular endothelial growth factor (VEGF) [33] and tumor necrosis factor alpha (TNF $\alpha$ ) [34], which can lead to an increase in the tortuosity of cerebral vessels [35]. As all these changes were detected a short time after SAH onset, our findings suggest that they promote long-term remodeling of cerebral vessels.

Since our study has a retrospective nature, it remains unclear whether aneurysm presence could promote an increase in its feeding artery tortuosity. In this case, the correlation between the presence on an aneurysm and tortuosity could be interpreted inversely. Lee et al. showed that aneurysmal arteries are characterized by decreased critical buckling pressure [36], which can lead to an increase in tortuosity [6]. However, another result of our study-the significantly lower ICA tortuosity among patients with mirror aneurysm - might not support that finding. Mirror aneurysms are characterized by a different etiology. They might result from congenital factors such as defects in cell migration during angiogenesis, which causes alterations of blood flow [37]. Such aneurysms exhibit a genetic predisposition and tend to rupture earlier in life [37]. Therefore, as mirror aneurysms are unlikely to be caused by an increase in tortuosity, our findings suggest that aneurysm presence might not meaningfully influence the tortuosity of its feeding artery. However, due to a small number of patients with mirror aneurysms who participated in our study, such conclusions demand further investigation.

A significant negative correlation between RL and ICA diameter was also observed in this study. A similar correlation was found in terms of coronary arteries [38]. The fact that a larger artery diameter could be caused by its wall weakening and increased blood flow [10] explains such correlation.

\section{Conclusions}

Higher tortuosity of ICA is associated with aneurysm presence in any of its intracranial segments. Tortuosity is increased in female patients and patients with a history of SAH. ICA tortuosity is significantly lower among patients with mirror aneurysms, positively correlated with time after SAH, and negatively correlated with ICA diameter.

Our study was mainly limited by the study group size and the fact that our control group consisted of patients with aneurysms located in other arteries than ICA. The inability to determine influence of aneurysm presence on its feeding artery tortuosity can be viewed as another limitation. This was addressed in our findings.

Author Contributions: Formal analysis, K.M.K. and J.G.; Funding acquisition, K.S.; Investigation, K.M.K.; Methodology, K.M.K.; Resources, R.M.K.; Software, K.M.K.; Supervision, R.M.K., B.M.K., K.S. and J.G.; Visualization, K.M.K.; Writing—original draft, K.M.K., R.M.K., B.M.K. and J.G.; Writing—review \& editing, B.M.K.

Funding: This work was supported by the National Science Center-Poland (grant number 2014/15/N/ NZ4/01062) to Roger M. Krzyżewski and by the Ministry of Science and Higher Education, Republic of Poland, under project "Diamentowy Grant 2018" (grant number DI2017 005747) to Kornelia M. Kliś. The funders had no role in study design, in the collection, analysis and interpretation of data, in the writing of the report and in the decision to submit the article for publication.

Conflicts of Interest: The authors declare no conflict of interest.

\section{References}

1. Owen, C.G.; Newsom, R.S.B.; Rudnicka, A.R.; Barman, S.A.; Woodward, E.G.; Ellis, T.J. Diabetes and the tortuosity of vessels of the bulbar conjunctiva. Ophthalmology 2008, 6, 27-32. [CrossRef] [PubMed]

2. Hughes, A.D.; Martinez-Perez, E.; Jabbar, A.S.; Hassan, A.; Witt, N.W.; Mistry, P.D.; Chapman, N.; Stanton, A.V.; Beevers, G.; Pedrinelli, R.; et al. Quantification of topological changes in retinal vascular architecture in essential and malignant hypertension. J. Hypertens. 2006, 24, 889-894. [CrossRef] [PubMed] 
3. Li, Y.; Shen, C.; Ji, Y.; Feng, Y.; Ma, G.; Liu, N. Clinical implication of coronary tortuosity in patients with coronary artery disease. PLoS One 2011, 6, 24232. [CrossRef] [PubMed]

4. Sasongko, M.B.; Wong, T.Y.; Nguyen, T.T.; Cheung, C.Y.; Shaw, J.E.; Wang, J.J. Retinal vascular tortuosity in persons with diabetes and diabetic retinopathy. Diabetologia 2011, 54. [CrossRef] [PubMed]

5. Amemiya, T.; Bhutto, I.A. Retinal vascular changes and systemic diseases: Corrosion cast demonstration. Ital. J. Anat. Embryol. 2001, 106, 237-244. [PubMed]

6. Han, H.C. Twisted blood vessels: Symptoms, etiology and biomechanical mechanisms. J. Vasc. Res. 2012, 49, 185-197. [CrossRef] [PubMed]

7. Ruan, L.-T.; Duan, Y.-Y.; Cao, T.-S.; Zhuang, L.; Huang, L. Color and power Doppler sonography of extracranial and intracranial arteries in Moyamoya disease. J. Clin. Ultrasound 2006, 34, 60-69. [CrossRef] [PubMed]

8. Kim, B.J.; Kim, S.M.; Kang, D.-W.; Kwon, S.U.; Suh, D.C.; Kim, J.S. Vascular tortuosity may be related to intracranial artery atherosclerosis. Int. J. Stroke 2015, 10, 1081-1086. [CrossRef]

9. Spangler, K.M.; Challa, V.R.; Moody, D.M.; Bell, M.A. Arteriolar tortuosity of the white matter in aging and hypertension. A microradiographic study. J. Neuropathol. Exp. Neurol. 1994, 53, 22-26. [CrossRef]

10. Dobrin, P.B.; Schwarcz, T.H.; Baker, W.H. Mechanisms of arterial and aneurysmal tortuosity. Surgery 1988, 104, 568-571. [PubMed]

11. Lee, K.M.; Choi, S.Y.; Kim, M.U.; Lee, D.Y.; Kim, K.A.; Park, S. Effects of anatomical characteristics as factors in abdominal aortic aneurysm rupture: CT aortography analysis. Medicine (Baltimore). 2017, 96, 7236. [CrossRef] [PubMed]

12. Majeski, J. Splenic artery tortuosity simulating a splenic artery aneurysm. South. Med. J. 1998, 91, 949-951. [CrossRef] [PubMed]

13. Labeyrie, P.-E.; Braud, F.; Gakuba, C.; Gaberel, T.; Orset, C.; Goulay, R.; Emery, E.; Courthéoux, P.; Touzé, E. Cervical artery tortuosity is associated with intracranial aneurysm. Int. J. Stroke 2017, 12, 549-552. [CrossRef] [PubMed]

14. Kim, B.J.; Lee, S.H.; Kwun, B.D.; Kang, H.G.; Hong, K.-S.; Kang, D.-W.; Kim, J.S.; Kwon, S.U. Intracranial aneurysm is associated with high intracranial artery tortuosity. World Neurosurg. 2018, 112, 876-880. [CrossRef] [PubMed]

15. Kliś, K.M.; Krzyżewski, R.M.; Kwinta, B.M.; Stachura, K.; Moskała, M.; Tomaszewski, K.A. Computer-aided analysis of middle cerebral artery tortuosity: Association with aneurysm development. J. Neurosurg. 2017, 1-7. [CrossRef] [PubMed]

16. Virgilio, F.; Maurel, B.; Davis, M.; Hamilton, G.; Mastracci, T.M. Vertebral tortuosity index in patients with non-connective tissue disorder-related aneurysm disease. Eur. J. Vasc. Endovasc. Surg. 2017, 53, 425-430. [CrossRef] [PubMed]

17. Krzyżewski, R.M.; Kliś, K.M.; Kwinta, B.M.; Gackowska, M.; Stachura, K.; Starowicz-Filip, A.; Thompson, A.; Gąsowski, J. Analysis of anterior cerebral artery tortuosity: association with anterior communicating artery aneurysm rupture. World Neurosurg. 2018. [CrossRef] [PubMed]

18. Rikhtegar, F.; Knight, J.A.; Olgac, U.; Saur, S.C.; Poulikakos, D.; Marshall, W.; Cattin, P.C.; Alkadhi, H.; Kurtcuoglu, V. Choosing the optimal wall shear parameter for the prediction of plaque location-A patient-specific computational study in human left coronary arteries. Atherosclerosis 2012, 221, $432-437$. [CrossRef]

19. Meng, H.; Tutino, V.M.; Xiang, J.; Siddiqui, A. High WSS or Low WSS? Complex interactions of hemodynamics with intracranial aneurysm initiation, growth, and rupture: toward a unifying hypothesis. Am. J. Neuroradiol. 2014, 35, 1254-1262. [CrossRef] [PubMed]

20. Hoi, Y.; Zhou, Y.-Q.; Zhang, X.; Henkelman, R.M.; Steinman, D.A. Correlation between local hemodynamics and lesion distribution in a novel aortic regurgitation murine model of atherosclerosis. Ann. Biomed. Eng. 2011, 39, 1414-1422. [CrossRef]

21. Sugiyama, S.; Niizuma, K.; Nakayama, T.; Shimizu, H.; Endo, H.; Inoue, T.; Fujimura, M.; Ohta, M.; Takahashi, A.; Tominaga, T. Relative residence time prolongation in intracranial aneurysms: A possible association with atherosclerosis. Neurosurgery 2013, 73, 767-776. [CrossRef] [PubMed]

22. Zhang, J.; Liu, Q.; Han, H.-C. An in vivo rat model of artery buckling for studying wall remodeling. Ann. Biomed. Eng. 2014, 42, 1658-1667. [CrossRef] [PubMed] 
23. Shen, M.; Lee, J.; Basu, R.; Sakamuri, S.S.V.P.; Wang, X.; Fan, D.; Kassiri, Z. Divergent roles of matrix metalloproteinase 2 in pathogenesis of thoracic aortic aneurysm. Arterioscler. Thromb. Vasc. Biol. 2015, 35, 888-898. [CrossRef] [PubMed]

24. Togay-Işikay, C.; Kim, J.; Betterman, K.; Andrews, C.; Meads, D.; Tesh, P.; Tegeler, C.; Oztuna, D. Carotid artery tortuosity, kinking, coiling: Stroke risk factor, marker, or curiosity? Acta Neurol. Belg. 2005, 105, 68-72. [PubMed]

25. Chiha, J.; Mitchell, P.; Gopinath, B.; Burlutsky, G.; Kovoor, P.; Thiagalingam, A. Gender differences in the prevalence of coronary artery tortuosity and its association with coronary artery disease. IJC Hear. Vasc. 2017, 14, 23-27. [CrossRef] [PubMed]

26. Horikoshi, T.; Akiyama, I.; Yamagata, Z.; Sugita, M.; Nukui, H. Magnetic resonance angiographic evidence of sex-linked variations in the circle of willis and the occurrence of cerebral aneurysms. J. Neurosurg. 2002, 96, 697-703. [CrossRef]

27. Lindekleiv, H.M.; Valen-Sendstad, K.; Morgan, M.K.; Mardal, K.-A.; Faulder, K.; Magnus, J.H.; Waterloo, K.; Romner, B.; Ingebrigtsen, T. Sex differences in intracranial arterial bifurcations. Gend. Med. 2010, 7, 149-155. [CrossRef]

28. Hamdan, A.; Barnes, J.; Mitchell, P. Subarachnoid hemorrhage and the female sex: Analysis of risk factors, aneurysm characteristics, and outcomes. J. Neurosurg. 2014, 121, 1367-1373. [CrossRef]

29. Krzyżewski, R.M.; Kliś, K.M.; Kucala, R.; Polak, J.; Kwinta, B.M.; Starowicz-Filip, A.; Stachura, K.; Piszczek, K.; Moskała, M.; Tomaszewski, K.A. Intracranial aneurysm distribution and characteristics according to gender. Br. J. Neurosurg. 2018, 32, 541-543. [CrossRef]

30. Sehba, F.A.; Mostafa, G.; Knopman, J.; Friedrich, V.; Bederson, J.B. Acute alterations in microvascular basal lamina after subarachnoid hemorrhage. J. Neurosurg. 2004, 633-640. [CrossRef]

31. Vikman, P.; Beg, S.; Khurana, T.; Hansen-Schwartz, J.; Edvinsson, L.; Edvinsson, L. Gene expression and molecular changes in cerebral arteries following subarachnoid hemorrhage in the rat. J. Neurosurg. 2006, 105, 438-444. [CrossRef] [PubMed]

32. Kylstra, J.A.; Wierzbicki, T.; Wolbarsht, M.L.; Landers, M.B.; Stefansson, E. The relationship between retinal vessel tortuosity, diameter, and transmural pressure. Graefes Arch. Clin. Exp. Ophthalmol. 1986, 224, 477-480. [CrossRef] [PubMed]

33. Jośko, J. Cerebral angiogenesis and expression of VEGF after subarachnoid hemorrhage (SAH) in rats. Brain Res. 2003, 981, 58-69. [CrossRef]

34. Ostrowski, R.P.; Colohan, A.R.; Zhang, J.H. Molecular mechanisms of early brain injury after subarachnoid hemorrhage. Neurol. Res. 2006, 28, 399-414. [CrossRef] [PubMed]

35. Robinson, R.; Ho, C.E.H.; Tan, Q.S.W.; Luu, C.D.; Moe, K.T.; Cheung, C.Y.; Wong, T.Y.; Barathi, V.A. Fluvastatin downregulates VEGF-A expression in TNF- $\alpha$-induced retinal vessel tortuosity. Investig. Opthalmology Vis. Sci. 2011, 52, 7423-7431. [CrossRef]

36. Lee, A.Y.; Sanyal, A.; Xiao, Y.; Shadfan, R.; Han, H.-C. Mechanical instability of normal and aneurysmal arteries. J. Biomech. 2014, 47, 3868-3875. [CrossRef]

37. Baccin, C.E.; Krings, T.; Alvarez, H.; Ozanne, A.; Lasjaunias, P. Multiple mirror-like intracranial aneurysms. Report of a case and review of the literature. Acta Neurochir. 2006, 148, 1091-1095. [CrossRef]

38. Hutchins, G.M.; Miner, M.M.; Bulkley, B.H. Tortuosity as an index of the age and diameter increase of coronary collateral vessels in patients after acute myocardial infarction. Am. J. Cardiol. 1978, 41, 210-215. [CrossRef]

(C) 2019 by the authors. Licensee MDPI, Basel, Switzerland. This article is an open access article distributed under the terms and conditions of the Creative Commons Attribution (CC BY) license (http://creativecommons.org/licenses/by/4.0/). 